\title{
LabVIEW BASED SELF TUNING FUZZY LOGIC CONTROLLER FOR STERILIZING EQUIPMENTS IN HOSPITALS
}

\author{
P. Hari Krishnan ${ }^{1}$, C.Vaishnavi ${ }^{2}$ \\ ${ }^{1}$ Assistant professor, Department of EEE, Anna University Regional Centre - Coimbatore, Tamil Nadu, India \\ ${ }^{2} P G$ Scholar, Department of C\&I, Anna University Regional Centre - Coimbatore, Tamil Nadu, India
}

\begin{abstract}
In this paper, temperature monitoring of sterilizing equipment system was established with the help of fuzzy and self tuning fuzzy logic controller designed in LabVIEW software. It combines the advantages of both fuzzy logic and self tuning fuzzy logic controller. The implementation attempts to rectify the errors between the obtained value and the given point which helps to achieve efficient temperature control. With the help of the rules the fuzzy controllers manage the system depend on the obtained values and the difference in the both temperature (errors). The simulation results presented in order to evaluate the proposed method. From the result the self tuning fuzzy logic controller was forbearing to any kind of interruption and the temperature control is most accurate.
\end{abstract}

Keywords - Sterilizing system, LabVIEW, Self tuning fuzzy logic controller

\section{INTRODUCTION}

In most of the hospitals, sterilization of equipments is done to avoid the infection. For sterilization, the temperature of the water should be controlled. In this paper, it is done using self tuning fuzzy logic controller. It was the process of switching over a crisp values to a fuzzy values, crisp portions are rehabilitated to fuzzy portions, which turns exact crisp input codes in to grammatical codes which are currently used in wide variety of engineering applications. The fuzzy logic deduces an easy structure that can be understood by the human analyzing capabilities. The main motive for moving over fuzzy was minimalism in scheming compare to the classical controller. Apart from the beneficial part it has some difficulties, which contains complication in framing the rules which lead to the addition of intricacy in the process. The sequential arrangement of the electronic devices and equipments which offers the steadiness and precision is called process control system. Generally the equipments of anesthetic and its belonging apparatus are suggested for thermal disinfection. This process of sterilization will kill the pathogenic micro organisms which are present on the equipments.

\section{SYSTEM DESCRIPTION}

The sterilizing system generally consists of the following description. The desired temperature was given to the system through keyboard. The actual temperature was sensed by sensor and converted to digital signal by the A/D converter. The computer reads the actual temperature and compares with desired temperature. If it finds any difference then it sends signal to switch ON/OFF the relay through D/A converter and amplifier. Then the LabVIEW software acts as a controller which corrects the error. Thus the system automatically corrects any changes in output. Since there is more complexity it also provides simple procedure to obtain output.

The main parts of the sterilizing process consist of mainly water container, data acquisition system, central processing unit, sensor, LabVIEW controller and heater. For the distribution of the heat the stirrer was used.

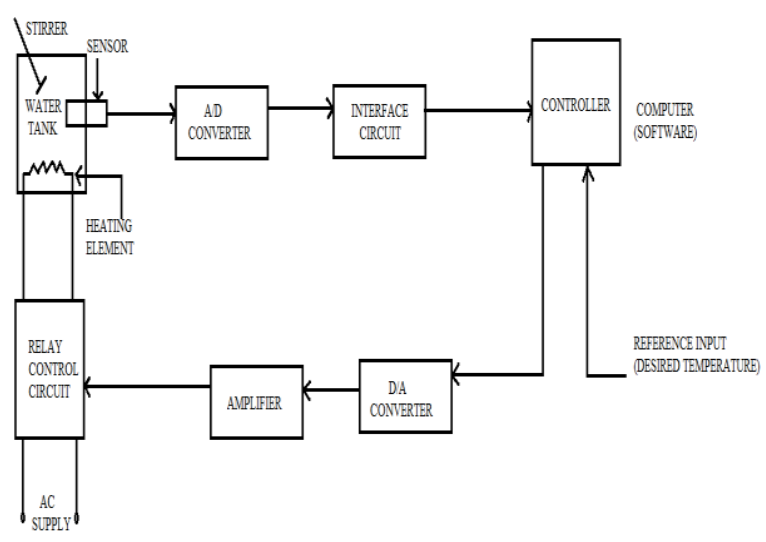

Fig -1: Block diagram of the sterilizing system

The Sensor used was thermocouple. DAQ act as interface circuit of sensor and controller. It also links the controller and driver circuit. To increase the range of sensor, the amplifier circuit is used. The functioning of this sterilizing system describes that, when the sensor sense the temperature from the hot water of the tank will be converted to the digital signal ,so that the DAQ can easily sends the signal (voltage) to the controller. The value obtained by subtracting the assigned value and the measured value (error) is given to the controller. Those signals will given in the form of analog signal to operate the relay. 


\subsection{Thermal Disinfection}

Sterilization process is generally processed by allowing the steam to contains which are placed in the tray of sterilizing tank, in which sterilizing can also be produced accurately by thermal disinfection. This process was done for several length of time where the equipments should be contacted with the heated water. The time decreases by increase in temperature. Draft international standards will suddenly alter the settings necessary for disinfection by allowing the hot water into the mechanical washing machine. The process was done very deliberately which will not allow the patient to be sick again.

\subsection{System Identification}

System identification was done by using MATLAB system identification tool box. Here sterilizing system was a one input one output system .due to this condition the system order is one. When we apply the input to the system, the process will take some time for heating process. When the system is switched off, it will take some time to come to the initial condition.

\section{DESIGN PROCEDURES}

The parameters to be guarded is the process variable, such as physical variables, then the assigned values is the required values for the controlled parameters. The result will be regulated by the fuzzy controller. This result will ride the process capricious to the assigned values.

\subsection{FLC}

Fuzzy logic was an extra effectual in response control system. The FLC processes were declared as the consumer defined set of laws leading the systems; the alternation in the controller can be customized without any difficulty to illustrate the flexible quality of the controller. For many number of inputs the system can be constructed effortlessly with the aid of rule based function. The fuzzy logic controller helps out in convening the nonlinear function. Even though there are more advantages, rising the rules will increase the complication of process. Sterilizing system was nonlinear, but nonlinear system concept were inadequate and complicated to plan; therefore the nonlinear system should be linearized. The adjustment of the linear control of nonlinear systems requires. The sterilizing system uses the twodimensional fuzzy controller model. The controller can be designed for linearized model easily but it should also operate in different conditions.

\subsection{Fuzzification}

It was the process of switching over a crisp values to a fuzzy values, crisp portions are rehabilitated to fuzzy portions which turns exact crisp input codes in to grammatical codes. In a real life world, the quantities that we consider may be thought of as crisp, accurate and deterministic, but actually they are not so, they possess uncertainty within themselves. The uncertainty may arise due to vagueness, imprecision or uncertainty. Commonly three type of fuzzification where performed.

\subsection{Defuzzification}

Defuzzification is a surveying procedure from a zone of fuzzy control activities described over an output cosmos of conversion into a region of crisp (non fuzzy) control activities. This process is necessary because in most of the real time applications to operate the controller the crisp sets are required. This process will yield fuzzy control action. There are numerous method of defuzzification, accounting $n$ it only few methods are used commonly.

\subsection{Membership Function}

Membership function characterizes the indistinctness in a fuzzy position impartial of the rudiments in the set. The illustration of these where commonly in the graphical appearances. To symbolize the indistinctness there are numerous ways, likewise there are plenty of ways to describe the membership function. Membership function elaborates all the data enclosed in a fuzzy set. In many ways we can allocate membership principles to fuzzy capricious in assessment with the chance solidity function to random variables. Allocating membership values has several methods.

\subsection{Formation of Rules}

The logic was obtained by exaggerating a process of human pronouncement, where system control is attained from the acquaintance of the control set of laws and syntactical capricious. The rules are in "If Then" format and the If side was called the conditions and the Then side was the conclusion. The relationships among the entry and the production of grammatical capricious are illustrated by the rules. Detecting problems in large rule bases was difficult. If the morphological provisions are same in the input then the grammatical variable has the identical quantity of linguistic expressions. For fuzzy systems with many number of controller inputs, the cascading fuzzy system is used to avoid large rule bases. Likewise the rules can be formed.

\subsection{Self Tuning Fuzzy Logic Controller}

The adaptive controller was being composed of two loops. The loops were differentiated by their process. The interior region contains the course of action and a normal response controller. The superficial region adapts the constraints of the regulator, which was derived by mathematical computation. Sometimes without introducing probing control signal it was not possible to estimate the process specification. The systems contour is computerization of progression planning and blueprint, for each sampling period the progression replica and the managing plan are updated. This construction type of the controller can operate its constraint without any human intervention to gain the preferred output of the system. 


\section{SIMULATIONS AND RESULTS}

The performance of the self tuning FLC triumph over the flaw of the other controller The settling time is very low as compared with the common fuzzy logic controller. Then errors were minimized. From the simulation result of the FLC controller, found the variation of input scaling factors and output scaling factors variation for various set points. Three methods for designing self-tuning fuzzy logic controller are

- $\quad$ Varying the shape of membership function

- Change the tuning Rules

- Change the scalar Gains.

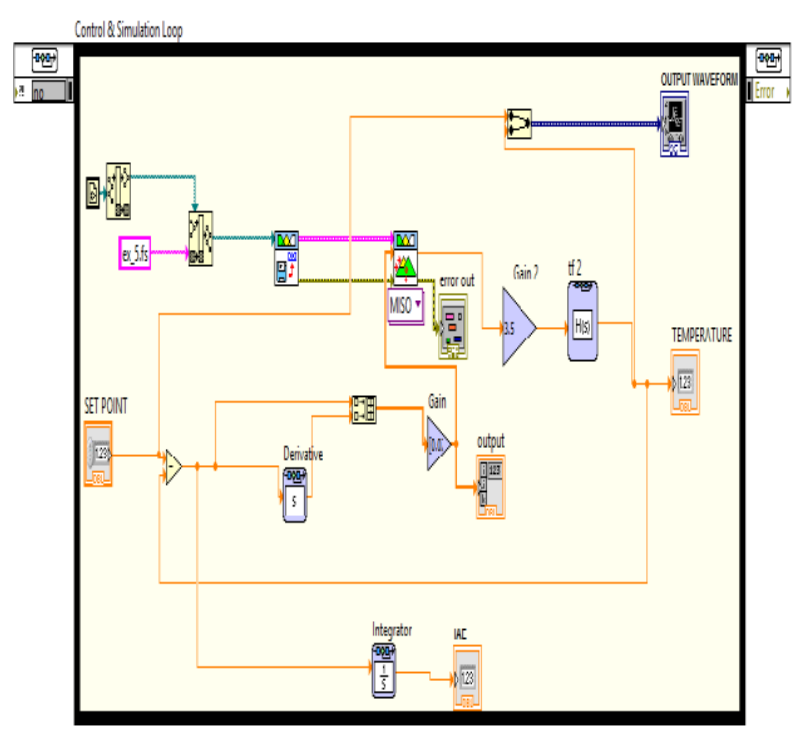

Fig-2:.Simulation Block diagram of fuzzy logic controller

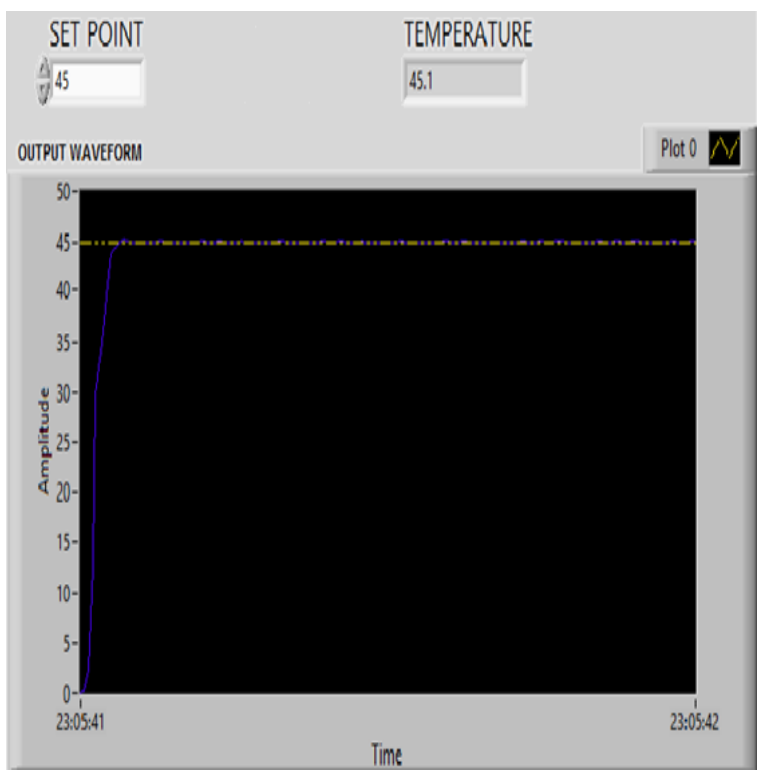

Fig.-3:.Output response of the FLC

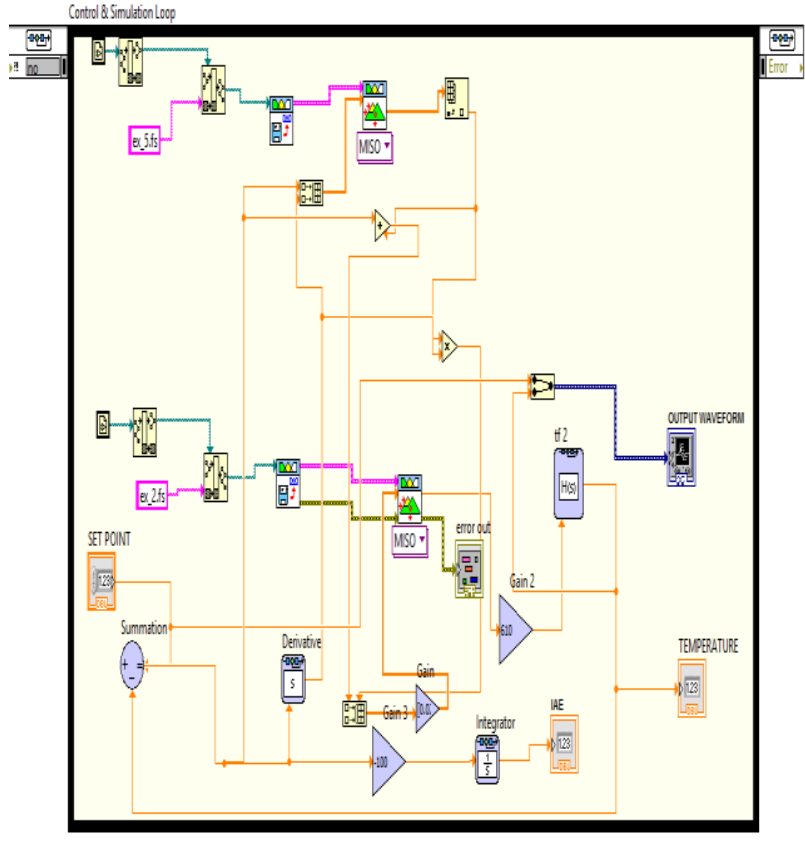

Fig.-4: Simulation Block diagram of Self-tuning FLC

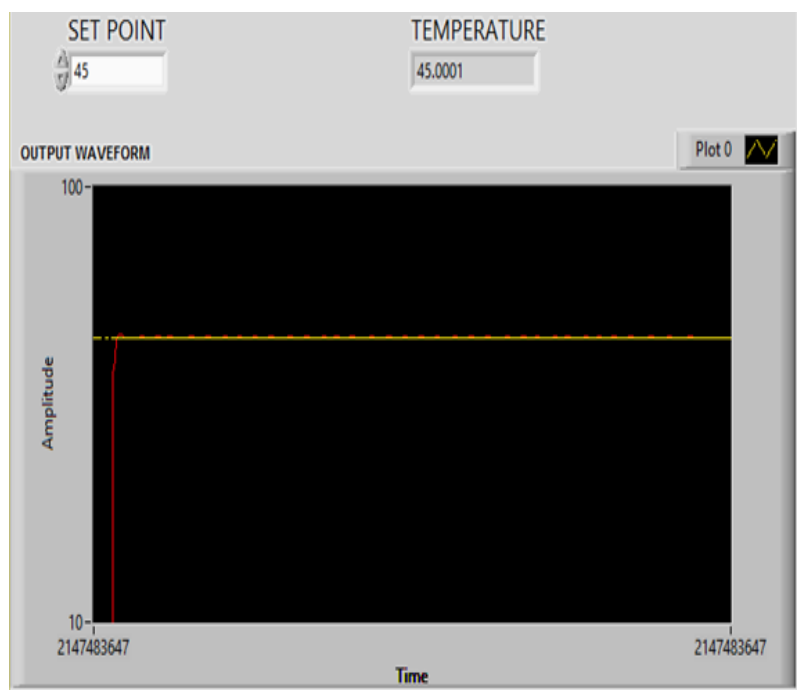

Fig-.5: Output Response of the self tuning FLC

Then the simulation of the self tuning was performed, here the output which derived from the fuzzy loop corrected inevitably.Thus it provides better simulation results. The output which comes out from the fuzzy comes out with a minute errors thus the self tuning controller automatically corrects the output to the desired values.

\section{CONCLUSIONS}

In this paper, the temperature control processing of self tuning FLC was designed. It has been shown that the proposed controller was processing better than the other controllers. To simulate the result we have used the help of LabVIEW software. Then the final value of the proposed controller was more close to the desired value. Future work includes, adding more parameters in the control process. 


\section{ACKNOWLEDGEMENTS}

I would like to acknowledge and extend my heartfelt gratitude to my guide-Assistant Professor P.Hari Krishnan, for his vital encouragement and patience guidance, generous assistance and invaluable advice, all of which have been of inestimable worth to the completion of my paper. Finally, my thanks would also go to my beloved parents for me boundless love and whole-hearted support over all these past years.

\section{REFERENCES}

[1] C. C. Lee.1990 Fuzzy logic in control systems 1990: Fuzzy logic controller-Part I IEEE Trans. Syst.

[2] C.C .Lee.1999 Fuzzy logic in control systems: Fuzzy logic controller-Part II IEEE Trans. Syst.

[3] K. Shimojima, T. Fukuda, and Y. Hasegawa, 1995 Self-tuning fuzzy modelling with adaptive membership function, rules, and hierarchical structure based on genetic algorithm.

[4] Karl John Astrom and Bjorn Witten mark, 1998 Adaptive control, second edition.

[5] P. Melba Mary1 N.S. Marimuthu 2007.Design of selftuning fuzzy logic controller for the control of an unknown industrial process, International journal for soft computing.

[6] C.Treesatayapun, S.Uatrongjit and K.Kantapanit. 2002 Fuzzy Graphic Rule Network and Its Application on Water Bath Temperature Control System, American control conference.

[7] Wahid N. 2012 Self-Tuning fuzzy PID controller design for aircraft pitch control, intelligent systems modelling \& simulation.

[8] M.Guzelkaya, I.Eksin, Eyesil. 2003. Self-Tuning PID type fuzzy logic controller Co-efficient via relative rate observer, Engineering Application of Artificial intelligence.

[9] M Braae, DA Rutherford.1979.Selection parameter for fuzzy logic controller, Fuzzy sets and Systems.

[10] CP Pappis, EH Mamdani.1977.Fuzzy logic controller for traffic junction, Man and Cybernetics.

[11] Rahul Malhotra, Rajender sodhi, "Boiler flow control using PID and Fuzzy logic controller,'IJCSET, Vol 1, Issue 6,315-319 july 2011.

[12] Cheong.F,Lai,.R, Constraining the Optimization of a Fuzzy Logic Controller Using an Enhanced Genetic Algorithm, IEEE Transaction on system, Man and Cybemetics, Vol 30, No.1, Feb 2000

[13] "Electrical and Electronic Measurements and instrumentation", A.K.Sawhney, Dhanpat Rai publication, $7^{\text {th }}$ edition 2005

\section{BIOGRAPHIES}

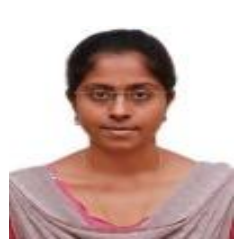

C.Vaishnavi was born in Vellore, India. He received his B.E degree in the department of Electrical \& Electronics Engineering from Anna University Chennai in 2012. She is pursuing M.E degree in the department of Control \&
Instrumentation Engineering from Anna University Chennai.

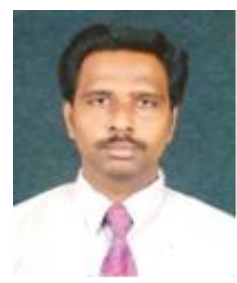

Hari Krishnan. P Was born in Madras (now Chennai). He received his BE degree in Electrical and Electronics of Madras University in 1997. Received his ME degree in Applied Electronics He is a Life member of MISTE. Currently he is working as Assistant professor in Anna University, Regional Centre, Coimbatore. His areas of interests include Image processing, Digital signal processing and Instrumentation 